\title{
Primary duodenal extraskeletal osteosarcoma-a case report
}

\author{
Harini Narayanappa ${ }^{1 *}$ and Ann Kurian ${ }^{2}$ \\ *Correspondence: docharini@outlook.com

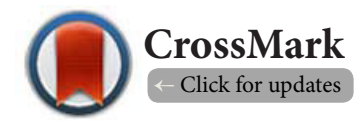 \\ 'Department of Pathology, Apollo Hospitals, Greams Road, Chennai, India. \\ ${ }^{2}$ Department of histopathology, Apollo Speciality hospitals, Teynampet, Chennai, India.
}

\begin{abstract}
Extraskeletal osteosarcoma is a rare malignant soft tissue tumour, which represents about $4 \%$ of all osteosarcomas and $1 \%$ of all soft tissue sarcomas. We present a case of extraskeletal osteosarcoma, albeit at a hitherto undescribed site, duodenum. This case report addresses the clinicopathological features and differential diagnosis of extraskeletal osteosarcoma and the importance of clinicopathological correlation in the diagnosis and workup of such cases.

Keywords: Extraskeletal osteosarcoma, duodenum, malignant soft tissue tumour, clinicopathological features
\end{abstract}

\section{Introduction}

Extraskeletal osteosarcoma is a malignant mesenchymal neoplasm that depicts malignant osteoid, bone and/or chondroid material. These tumours have no attachment to bone or periosteum, which has to be determined by the examination of radiological findings or observation during surgery $[1,3]$. It most commonly manifests in individuals older than 50 years with the lower extremity being the most common anatomic site, followed by the upper limb and the retroperitoneum $[1,4]$. We present a remarkable case of primary duodenal extra osseous osteosarcoma.

\section{Case presentation}

The patient was a 62 year old man who was admitted with history of intermittent pain abdomen of 3 years duration. There was no history of fever, vomiting, loss of appetite, loss of weight, diarrhoea or anti-tuberculosis treatment. Patient had no history of trauma or radiation therapy. Ultrasound scan abdomen showed a heterogeneous spherical mass measuring $13 \times 11 \times 9 \mathrm{~cm}$ arising from posterior wall of duodenum overlying renal hilum with central calcification occupying $20 \%$ of total area and eccentric calcification with irregular spiculated margins. Computed tomography of the abdomen revealed a large bulky mass involving duodenal and paraduodenal region with cholelithiasis (Figure 1). Endoscopic findings revealed a submucosal mass with superficial ulceration of duodenal mucosa. A biopsy performed was reported as a spindle cell lesion. Patient underwent Whipples' pancreaticoduodenectomy.
Intraoperative findings showed a large mass arising from $2^{\text {nd }}$ and $3^{\text {rd }}$ part of duodenum and on palpation appeared solid and cystic. Mass was adherent to inferior vena cava, Gerotas' fascia and perinephric fat on the right side. Macroscopic examination revealed a sub-mucosal duodenal mass measuring $11 \times 9 \times 8 \mathrm{~cm}$. Cut surface appeared solid-cystic, with cysts of varying sizes containing haemorrhagic fluid. Focal firm to hard calcified areas were seen within the lesion (Figure 2).

Microscopic examination revealed a cellular tumor involving the sub mucosa, muscularis propria and subserosa of the small intestinal wall with superficial mucosal ulceration. The tumor cells were arranged in short interlacing fascicles of spindle to epithelioid cells. The cells exhibited mild to moderate pleomorphism having eosinophilic cytoplasm, vesicular nuclei with prominent nucleoli. Mitosis of 32/50 HPF were noted. Areas of haemorrhage and dilated vascular channels were seen. Areas of osteoid were seen between the tumor cells with scattered osteoclastic giant cells (Figures $\mathbf{3 A}$ and $\mathbf{3 B}$ ). Foci of dystrophic calcification were noted. Adjacent pancreatic tissue was infiltrated by the tumor. Immunohistochemistry was performed; the tumor cells were positive for vimentin, osteonectin, $C D$ 68 and negative for CK, desmin, CKit, S100, CD34 and SMA (Figures 3C and 3D). A diagnosis of extraskeletal osteosarcoma was made. The patient had an uneventful post operative period and remains free of tumor a year after surgery.

\section{Discussion}

Extraskeletal osteosarcoma is an uncommon tumor and there 

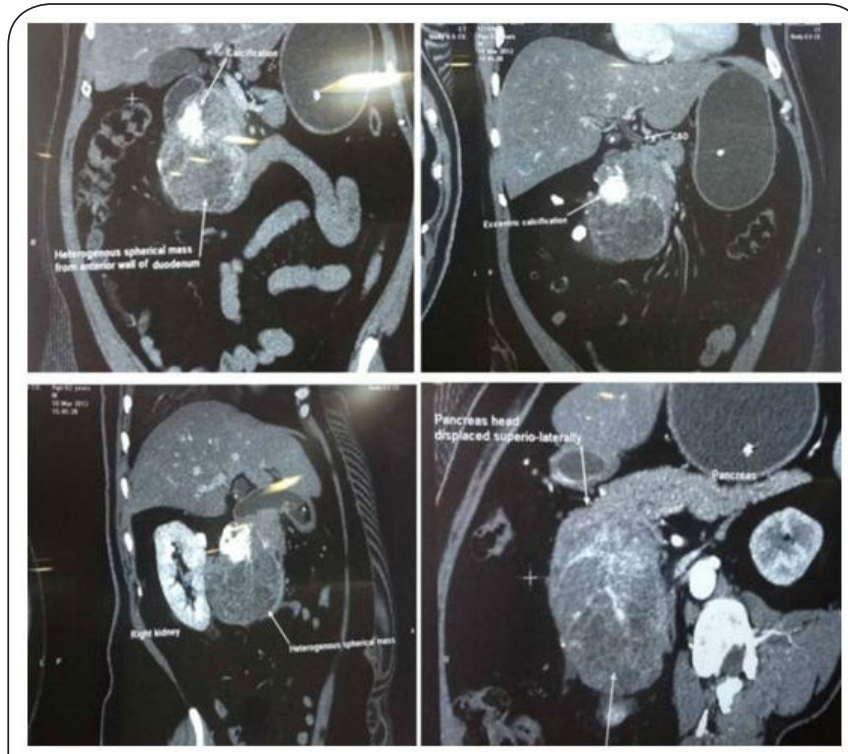

Figure 1. Heterogeneous mass with calcification.

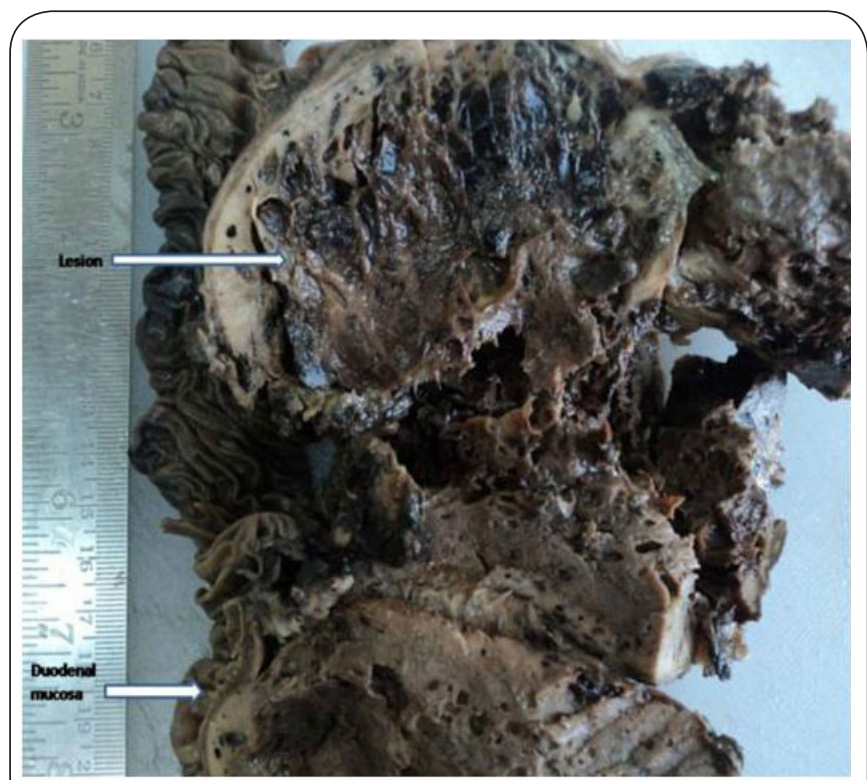

Figure 2. Submucosal duodenal mass with solid-cystic cut surface.

have been less than 50 cases reported so far [5]. Usually affects adults with a high incidence in patients older than 50 years and is slightly more common in males than in female patients [1]. The lower extremity is the most common site followed by upper limb and retroperitoneum $[4,6]$. Unusual sites, such as the larynx, kidney, oesophagus, small intestine, liver, heart, urinary bladder, parotid, and breast have been described $[4,6]$. The pathogenesis of the tumor is unclear, but prior history of radiation [4], a previous history of trauma at the tumor site and malignant transformation of myositis ossificans to extraskeletal osteosarcoma have been proposed [4].

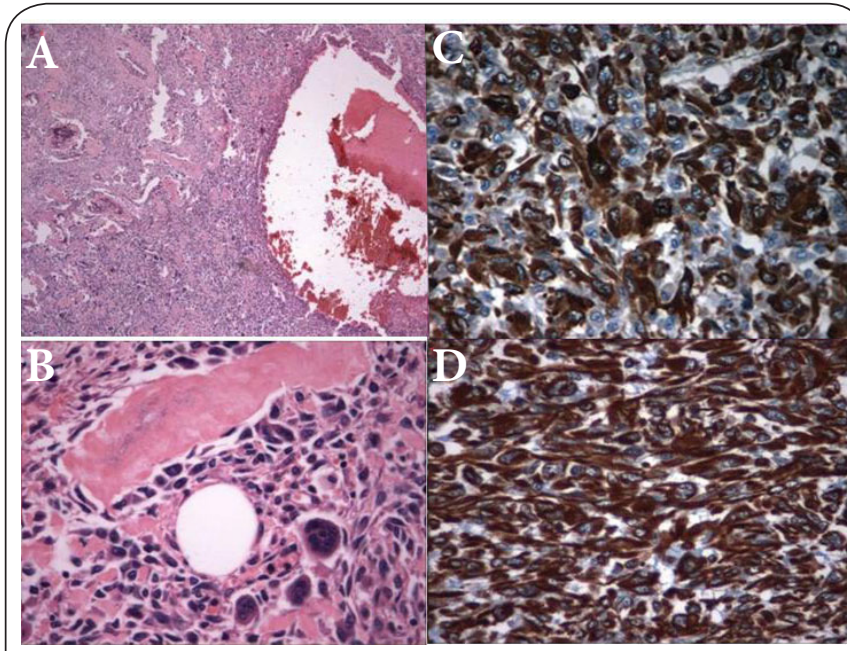

Figure 3. Tumor cells during mitosis and after immunohistochemitry analysis.

(A) Cellular lesion composed of tumor cells [H\&E, $\times 4$ ].

(B) Tumour cells with osteoid and osteoclastic gaint cells

[H\&E, $\times 40]$.

(C) Immunoreactivity of tumour cells to anti-osteonectin

[H\&E, $\times 40]$.

(D) Immunoreactivity of tumour cells to anti-vimentin [H\&E, $\times 40]$.

The histological patterns are varied as similar to osteosarcomas, which includes osteoblastic, fibroblastic/pleomorphic malignant fibrous histiocytoma like, chondroblastic, gaint cell MFH like, small cell, mixed and telangiectatic pattern. Nevertheless, the major predictor of clinical outcome was found to be the tumour size $(>5 \mathrm{~cm})$ according to the study by Bane et al [4]. According to ED B Chung and F M Enzinger, extraskeletal osteosarcoma with a prominent fibroblastic or MFH like component seemed to have a slightly better prognosis than predominantly osteoblastic, chondroblastic or telangiectatic types of the tumour [5]. The biological behaviour of well differentiated extraskeletal osteosarcoma has been suggested to be better than that of classical extraskeletal osteosarcoma, but some cases can progress to a higher grade [7]. It is necessary to distinguish extraskeletal osteosarcoma from other benign or malignant bone and cartilage forming soft tissue lesions. Amongst the malignant tumours, metaplastic bone is often seen in synovial sarcoma, malignant fibrous histiocytoma, dedifferentiated liposarcomas with osseous or cartilaginous elements, malignant peripheral nerve sheath tumour with heterologous elements, malignant melanoma and carcinosarcoma. Adequate sampling may be necessary to keep us from making an erroneous diagnosis. Extraskeletal osteosarcoma has to be distinguished from myositis ossificans which shows a characteristic zoning phenomenon with peripheral differentiation into well formed bone and a lack of cytologic atypia. A "reverse zoning phenomenon" with central osteoid material deposition and atypical cell proliferation at periphery is characteristic of sarcoma [4]. 
Elevated alkaline phosphatase levels has been accepted as a prognostic tumour marker in osteosarcomas [8], albeit, such high levels of alkaline phosphatase have also been reported in extraskeletal retroperitoneal osteosarcomas and is unlikely to be found in other retroperitoneal soft tissue tumours [9].

The immunohistochemical profile of vimentin, osteonectin CD 68 positivity and CK, desmin, cKit, S100, CD34 and SMA negativity supported the cytomorphology and favoured a diagnosis of extraskeletal osteosarcoma, as in our case. Osteocalcin and osteonectin help to distinguish malignant bone from collagen and cartilage matrix which is essential to the diagnosis of extraskeletal osteosarcoma [10]. To distinguish between low grade osteosarcoma and benign lesions, molecular analysis may be helpful that shows amplification of SAS, CDK4 and MDM2 genes in 12q 13-15 region in the former lesions [11].

According to a study by Lee JS and et al., patients with extraskeletal osteosarcoma generally have a poor prognosis and the majority develops metastatic disease within 3 years of diagnosis $[12,13]$. It has been reported that the overall mortality rates due to the tumor in the larger series exceeded $60 \%$ $[\mathbf{1}, \mathbf{2}, \mathbf{5}]$. Radical resection appears to be the best therapeutic option for local control but has no effect on distant metastasis [14]. Due to the rarity of cases, the efficacy of chemotherapy has not been evaluated although it has been the commonly used treatment modality [15]. Temporary palliative therapy includes radiotherapy [16], however understanding of the tumour biology and gene over-expression is required to enable efficient treatment.

\section{Conclusion}

Our case is illustrative of the well described extraskeletal osteosarcoma at an unusual site, duodenum. There is a need for a thorough sampling of the surgical specimen for documenting the presence of malignant osteoid and to exclude other differential diagnosis. Higher degree of accuracy in the diagnosis of such lesions requires clinical, radiological, histological and immunohistochemistry correlation.

\section{Competing interests}

The authors declare that they have no competing interests.

\section{Authors' contributions}

\begin{tabular}{|l|c|c|}
\hline Authors' contributions & HN & AK \\
\hline Research concept and design & $\checkmark$ & $\checkmark$ \\
\hline Collection and/or assembly of data & $\checkmark$ & -- \\
\hline Data analysis and interpretation & -- & $\checkmark$ \\
\hline Writing the article & $\checkmark$ & -- \\
\hline Critical revision of the article & $\checkmark$ & -- \\
\hline Final approval of article & $\checkmark$ & $\checkmark$ \\
\hline Statistical analysis & -- & -- \\
\hline
\end{tabular}

Acknowledgement

The authors would like to thank Dr. C S Mani and Dr. Suryakumar for contributing the clinical history and the radiological findings.

Publication history

Editor: Gjumrakch Aliev, GALLY International Biomedical Research and Consulting LLC, USA.

EIC: Giuseppe Musumeci, University of Catania, Italy.

Received: 18-Aug-2014 Final Revised: 15-Sep-2014

Accepted: 02-Oct-2014 Published: 09-Oct-2014

\section{References}

1. Allan $\mathrm{CJ}$ and Soule EH. Osteogenic sarcoma of the somatic soft tissues. Clinicopathologic study of $\mathbf{2 6}$ cases and review of literature. Cancer. 1971; 27:1121-33. | Article | PubMed

2. Sordillo PP, Hajdu SI, Magill GB and Golbey RB. Extraosseous osteogenic sarcoma. A review of 48 patients. Cancer. 1983; 51:727-34. | PubMed

3. Huvos AG. Clinicopathologic spectrum of osteogenic sarcoma. Recent observations. Pathol Annu. 1979; 14 Pt 1:123-44. | PubMed

4. Bane BL, Evans HL, Ro JY, Carrasco CH, Grignon DJ, Benjamin RS and Ayala AG. Extraskeletal osteosarcoma. A clinicopathologic review of 26 cases. Cancer. 1990; 65:2762-70. | Article | PubMed

5. Zhang HJ, Yang JJ, Lu JP, Sheng J, Yuan M, Jiang X, Li YX and Gupta S. Retroperitoneal extraskeletal osteosarcoma: imaging findings and transarterial chemoembolization. Cardiovasc Intervent Radiol. 2010; 33:430-4. | Article | PubMed

6. Chung EB and Enzinger FM. Extraskeletal osteosarcoma. Cancer. 1987; 60:1132-42. | Article | PubMed

7. Abramovici LC, Hytiroglou P, Klein RM, Karkavelas G, Drevelegas A, Panousi E and Steiner GC. Well-differentiated extraskeletal osteosarcoma: report of $\mathbf{2}$ cases, 1 with dedifferentiation. Hum Pathol. 2005; 36:439-43. | Article I PubMed

8. Narayanan S. Alkaline phosphatase as tumor marker. Ann Clin Lab Sci. 1983; 13:133-36.

9. Arai H, Rino Y, Nishii T, Yukawa N, Wada $\mathrm{N}$ and Oshiro $\mathrm{H}$ et al. Well differentiated extraskeletal osteosarcoma arising from the retroperitoneum that recurred as anaplastic spindle cell sarcoma. Hindawi Publishing Corporation. Case reports in medicine. 2010. I Article

10. Fanburg-Smith JC, Bratthauer GL and Miettinen M. Osteocalcin and osteonectin immunoreactivity in extraskeletal osteosarcoma: a study of 28 cases. Hum Pathol. 1999; 30:32-8. | Article | PubMed

11. Sabatier R, Bouvier C, de Pinieux G, Sarran A, Brenot-Rossi I, Pedeutour F, Chetaille B, Viens P, Weiller PJ and Bertucci F. Low-grade extraskeletal osteosarcoma of the chest wall: case report and review of literature. BMC Cancer. 2010; 10:645. I Article I PubMed Abstract I PubMed Full $\underline{\text { Text }}$

12. Lee JS, Fetsch JF, Wasdhal DA, Lee BP, Pritchard DJ and Nascimento AG. A review of $\mathbf{4 0}$ patients with extraskeletal osteosarcoma. Cancer. 1995; 76:2253-9. | Article | PubMed

13. Lee KH, Joo JK, Kim DY, Lee JS, Choi C and Lee JH. Mesenteric extraskeletal osteosarcoma with telangiectatic features: a case report. BMC Cancer. 2007; 7:82. | Article | PubMed Abstract | PubMed Full Text

14. Schneider JR, Sener SF and Barrera E, Jr. Combined replacement of infrarenal aorta and inferior vena cava after en bloc resection of retroperitoneal extraosseous osteosarcoma. J Vasc Surg. 2008; 48:4789. | Article | PubMed

15. Tao SX, Tian GQ, Ge MH and Fan CL. Primary extraskeletal osteosarcoma of omentum majus. World J Surg Oncol. 2011; 9:25. I Article I PubMed Abstract | PubMed Full Text

16. Goldstein-Jackson SY, Gosheger G, Delling G, Berdel WE, Exner GU, Jundt G, Machatschek JN, Zoubek A, Jurgens $\mathrm{H}$ and Bielack SS. Extraskeletal osteosarcoma has a favourable prognosis when treated like conventional osteosarcoma. J Cancer Res Clin Oncol. 2005; 131:520-6. | Article | PubMed

Citation:

Narayanappa $\mathrm{H}$ and Kurian A. Primary duodenal extraskeletal osteosarcoma-a case report. J Histol Histopathol. 2014; 1:9.

http://dx.doi.org/10.7243/2055-091X-1-9 